L OCKMEED MARTIN

ENVIRONMENTAL

RESTORATION

PROGRAM

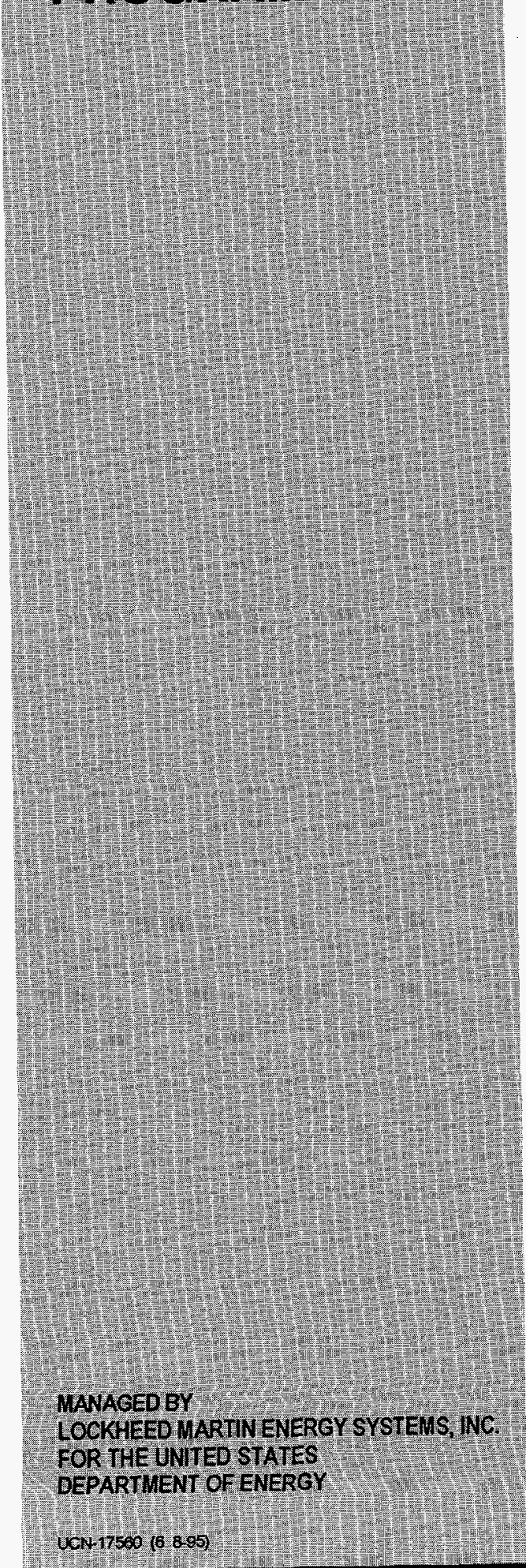

ORNL/ER-421

\section{Dry Well Conductivity Monitoring Report for Tanks W-8, W-9, and W-10, Oak Ridge National Laboratory, Oak Ridge, Tennessee}

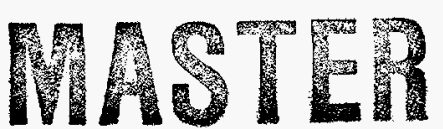

DISTRIOUTION OF THIS DOCUMENT is UuY? ph

This document has been approved by the ORNL Technical Information Office for release to the public. Date: $10 / 20 / 97$ 
ORNL/ER-421

\title{
Dry Well Conductivity Monitoring Report \\ for Tanks W-8, W-9, and W-10, Oak Ridge National Laboratory, Oak Ridge, Tennessee
}

Date Issued—October 1997

\author{
Prepared by \\ Vista Research, Inc. \\ Oak Ridge, Tennessee \\ under subcontract 78X-SP750C \\ Prepared for the \\ U.S. Department of Energy \\ Office of Environmental Management \\ under budget and reporting code EW 20 \\ Environmental Management Activities at \\ OAK RIDGE NATIONAL LABORATORY \\ Oak Ridge, Tennessee 37831 \\ managed by \\ LOCKHEED MARTIN ENERGY SYSTEMS, INC. \\ for the \\ U.S. DEPARTMENT OF ENERGY \\ under contract DE-AC05-84OR21400
}




\section{PREFACE}

This report, Dry Well Conductivity Monitoring Report for Tanks W-8,W-9 and W-10, Oak Ridge National Laboratory, Oak Ridge, Tennessee (ORNL/ER-421), was developed under Work Breakdown Structure 6.1.01.41.05.05.05 (Activity Data Sheet 3301, "WAG 1"). This document provides the Environmental Restoration Program with the dry well conductivity monitoring data and simulated liquid release tests results to support the use of Gunite and Associated Tanks (GAAT) W-8 and W-9 as temporary consolidation tanks during waste removal operations and the monitoring plans for Tank W-10 and the other tanks in the South Tank Farm during waste removal operations. Information provided in this report forms part of the technical basis for criticality safety, systems safety, engineering design, and waste management as they apply to the GAAT treatability study and waste removal actions. 


\section{DISCLAMIER}

Portions of this document may be illegible in electronic image products. Images are produced from the best available original document. 


\section{DISCLAIMER}

This report was prepared as an account of work sponsored by an agency of the United States Government. Neither the United States Government nor any agency thereof, nor any of their employees, make any warranty, express or implied, or assumes any legal liability or responsibility for the accuracy, completeness, or usefulness of any information, apparatus, product, or process disclosed, or represents that its use would not infringe privately owned rights. Reference herein to any specific commercial product, process, or service by trade name, trademark, manufacturer, or otherwise does not necessarily constitute or imply its endorsement, recommendation, or favoring by the United States Government or any agency thereof. The views and opinions of authors expressed herein do not necessarily state or reflect those of the United States Government or any agency thereof. 


\section{CONTENTS}

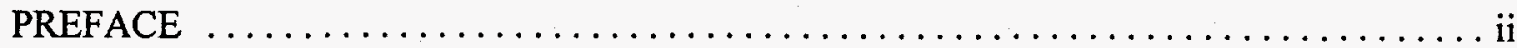

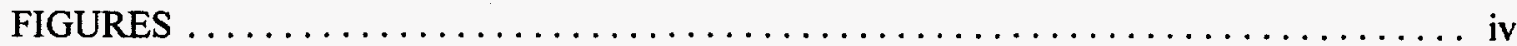

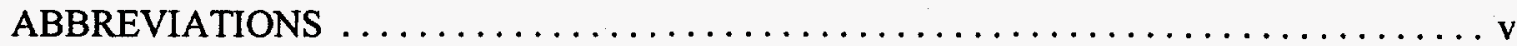

EXECUTIVE SUMMARY $\ldots \ldots \ldots \ldots \ldots \ldots \ldots \ldots \ldots \ldots \ldots \ldots \ldots \ldots \ldots \ldots \ldots$

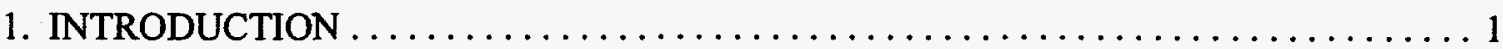

2. DRY WELL CONDUCTIVITY-MONITORING RESULTS

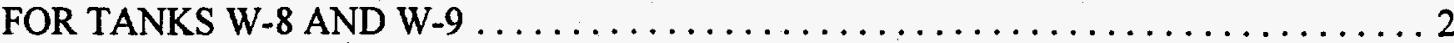

2.1 BASELINE DRY WELL CONDUCTIVITY MONITORING $\ldots \ldots \ldots \ldots \ldots \ldots \ldots$

2.2 SIMULATED LIQUID RELEASE TESTING ON TANKS W-8 AND W-9 $\ldots \ldots \ldots 7$

3. DRY WELL CONDUCTIVITY-MONITORING RESULTS FOR TANK W-10 $\ldots \ldots 10$

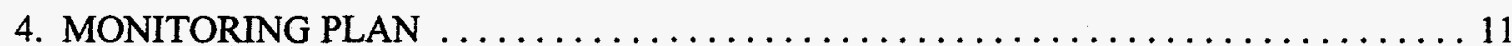

5. CONCLUSIONS AND RECOMMENDATIONS $\ldots \ldots \ldots \ldots \ldots \ldots \ldots \ldots \ldots \ldots \ldots \ldots \ldots \ldots$

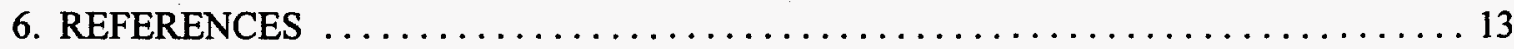




\section{FIGURES}

2.1 Plan view showing the location of the gunite tanks in the NTF and STF, including Tanks W-8, W-9, and W-10; the dry wells; and the SLR drain pipes DP-8, DP-9, and DP-10

2.2 Cut-away view of a typical STF tank showing the tank, dry well, and drain pipe for the SLR test 3

2.3 Cross section of DW-8 showing the location of the PVC screen and riser, the conductivity sensor, and the level of water in the dry well

2.4 Cross section of DW-9 showing the location of the PVC screen and riser, the conductivity sensor, and the level of water in the dry well $\ldots \ldots \ldots \ldots \ldots \ldots \ldots$

2.5 Plot of DW-9 baseline conductivity and cumulative rainfall data $\ldots \ldots \ldots \ldots \ldots \ldots$

2.6 Plot of DW-8 baseline conductivity, first SLR test and cumulative rainfall data . . . . 6

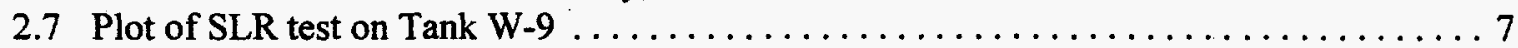

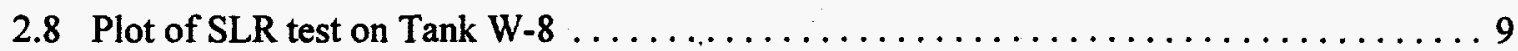

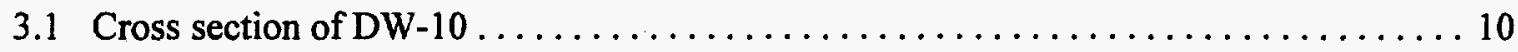

3.2 Plot of DW-10 baseline conductivity, SLR test and cumulative rainfall data . . . . . 11 


\section{ABBREVIATIONS}

CMM conductivity-monitoring method

GAAT Gunite and Associated Tanks

NTF

North Tank Farm

ORNL Oak Ridge National Laboratory

PVC polyvinyl chloride

SLR simulated liquid release

STF South Tank Farm 


\section{EXECUTIVE SUMMARY}

A treatability study and waste removal program are being implemented for the Gunite and Associated Tanks Operable Unit at Oak Ridge National Laboratory, Oak Ridge, Tennessee. Tanks W-3 and W-4 in the North Tank Farm are being used to evaluate in-tank sluicing as a means of removing radioactive sludges from the gunite tanks. This method will then be used to remove the sludges from the six tanks in the South Tank Farm (STF). To facilitate the transfer of processed sludges, Tank W-9 in the STF will be used as the primary consolidation tank and W-8 will be used as a backup tank. Previous structural and liquid integrity evaluations of W-8 and W-9 (Lockheed Martin Energy Systems, Inc. 1997a) have shown that they are structurally sound and do not leak. Nevertheless, while they are being used as consolidation tanks, they will be instrumented to ensure the detection of potential releases. The method of detection is by monitoring the electrical conductivity of the water in the dry well associated with each tank. Referred to as the conductivitymonitoring method (CMM) it will be used on all of the STF tanks during waste removal operations.

This report documents the instrumentation and monitoring efforts to establish baseline conductivity conditions. The simulated liquid release (SLR) testing reported here demonstrates the effectiveness of the CMM as a liquid-release detection method for consolidation Tanks W-8 and W-9 and Tank W-10 in the STF. The results show the remarkable sensitivity of the CMM to even very small simulated releases from the tank. The SLR testing for DW-8, DW-9 and DW-10 show that the dry well conductivity monitoring will be effective in detecting potential releases from the tanks during waste removal operations. The data in this report also make clear statements about the inferred integrity of the tanks, tank pads, and drain system:

1. The data substantiate earlier work and show that Tanks $\mathrm{W}-8, \mathrm{~W}-9$, and $\mathrm{W}-10$ are not leaking.

2. The data show that the pads under Tanks $\mathrm{W}-8, \mathrm{~W}-9$, and $\mathrm{W}-10$ are integral and connected to the dry wells.

3. The STF drain system appears to be functioning properly.

This report presents these results and describes the release monitoring plan for the consolidation tanks and during waste removal operations at all of the tanks in the STF. 


\section{INTRODUCTION}

A treatability study and waste removal program are being implemented for the Gunite and Associated Tanks (GAAT) Operable Unit at Oak Ridge National Laboratory (ORNL), Oak Ridge, Tennessee. Tanks W-3 and W-4 in the North Tank Farm (NTF) are being used to evaluate in-tank sluicing as a means of removing radioactive sludges from the gunite tanks. This method will then be used to remove the sludges from the six tanks in the South Tank Farm (STF). To facilitate the transfer of processed sludges, Tank W-9 in the STF will be used as the primary consolidation tank and W-8 will be used as a backup tank. Previous structural and liquid integrity evaluations of W-8 and W-9 (Lockheed Martin Energy Systems, Inc. 1997a) have shown that they are structurally sound and do not leak. Nevertheless, while they are in temporary use as a consolidation tanks, they will be instrumented to ensure the detection of potential liquid releases by monitoring the electrical conductivity of the water in the dry well associated with each tank. In addition, the dry well conductivity-monitoring method (CMM) will be used for release detection on all of the STF tanks during waste removal operations. This report documents the instrumentation, the monitoring efforts to establish baseline conductivity conditions, and the simulated liquid release (SLR) testing to demonstrate the effectiveness of the CMM as a liquid-release detection method for consolidation Tanks W-8 and W-9 and Tank W-10 in the STF.

The CMM makes use of the existing dry well system adjacent to each of the gunite tanks. These tanks are designed in such a way that any liquid that might be released will collect on the pad beneath the tank and from there drain into the dry well. The conductivity of the liquid in the gunite tanks is very high relative to that of the groundwater in the dry wells $-15,000$ to $30,000 \mu \mathrm{S} / \mathrm{cm}$ as compared with 200 to $500 \mu \mathrm{S} / \mathrm{cm}$. If a release were to occur, the conductivity of the water in the dry well would increase significantly as a result of the contribution from the tank Monitoring the conductivity of the water in the dry well can thus provide a viable means-and importantly, a means external to the tank-of detecting releases that might occur from the gunite tanks.

Monitoring conductivity levels in the dry wells as a release detection method was evaluated as part of the 1995 liquid integrity study (Lockheed Martin Energy Systems, Inc. 1996). The purpose of that study was to develop a method for real-time detection of potential releases during remediation activities that did not rely on tank-internal liquid level measurements. Such a method was desirable because it would allow continuous monitoring of liquid integrity, even while tank operations were underway. In 1996, CMM was evaluated in more detail, and simulated liquid-release demonstrations were conducted on Tanks W-3 and W-4 in the NTF (Vista Research, Inc. 1996). The results of the evaluation indicated that monitoring the conductivity of the water in the dry wells adjacent to the gunite tanks is a very effective method for real-time release detection and should be used as the primary release detection method during the treatability study and waste removal activities. Its application to the tanks in the STF needed to be demonstrated, however, before it could be used reliably as a monitoring tool.

The CMM has undergone field evaluation in the STF. The baseline conductivity monitoring for the dry wells adjacent to Tanks W-8, W-9, and W-10, as well as SLR testing of these, has been completed. A preliminary report on the results for Tank W-9 was issued at the end of July 1997 (Lockheed Martin Energy Systems, Inc. 1997b). This report documents the dry well conductivitymonitoring results for the temporary consolidation tanks, W-8 and W-9, as well as the results for Tank W-10. Chapter 2 of this report presents the results for Tanks W-8 and W-9. Chapter 3 presents 
the results for Tank W-10. The monitoring plans for the consolidation tanks and waste removal operations are described in Chap. 4. Conclusions and recommendations are given in Chap. 5, and the references are listed in Chap. 6.

\section{DRY WELL CONDUCTIVITY-MONITORING RESULTS FOR TANKS W-8 AND W-9}

Tanks W-8 and W-9 are located in the STF, as shown in Fig. 2.1. Dry well DW-8 is at the southwest corner of Tank W-8, and dry well DW-9 is on the northwest corner of Tank W-9. In both dry wells, 4-in.-diam polyvinyl chloride (PVC) well screens and risers were installed along with conductivity sensors. The sensors measure the electrical conductivity of the groundwater at the bottom of the dry well. The configuration of the sensor inside the PVC pipe in a dry well is illustrated in the cut-away view of an STF tank shown in Fig. 2.2. The sensors have been used to collect baseline conductivity data for the dry wells and to measure changes in conductivity during the SLR tests on the tanks. For the SLR tests on W-8 and W-9, a 1.25-in.-diam steel pipe with a screened drive point was installed on the side of the tank farthest from the dry well (see Fig. 2.2). The pipe was driven downward from the surface ( $6 \mathrm{ft}$ above the tank) parallel to the vertical wall of the tank and directly adjacent to it. The drain pipe, or "SLR pipe," is the mechanism whereby solutions of water and potassium chloride were introduced to simulate leaks from the tank.

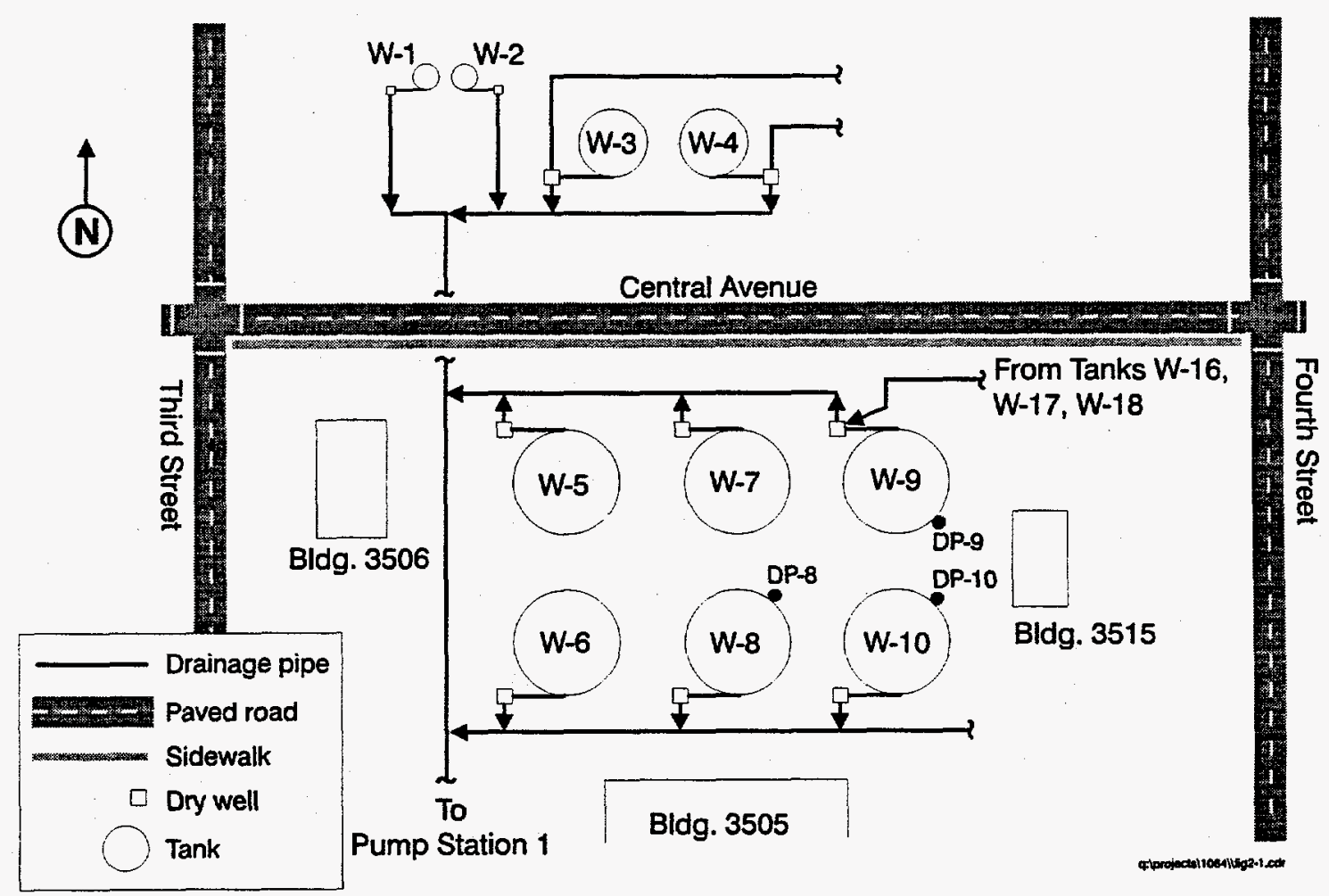

Fig. 2.1. Plan view showing the location of the gunite tanks in the NTF and STF, including TanksW-8,W-9, and W-10; the dry wells; and the SLR drain pipes DP-8, DP-9, and DP-10. 
Fig. 2.2, as stated above, shows the relative locations of an STF gunite tank and dry well. This figure is illustrative of tank, pad, and dry well construction in the STF. Because the STF drain system keeps the groundwater level below the bottom of the pad, one can see how a potential release from a tank would be expected to flow onto the pad and from there into the dry well. The conductivity sensors at the bottom of dry wells can therefore be used to collect baseline measurements of groundwater conductivity under ambient conditions and to measure the changes in conductivity produced during the SLR tests.

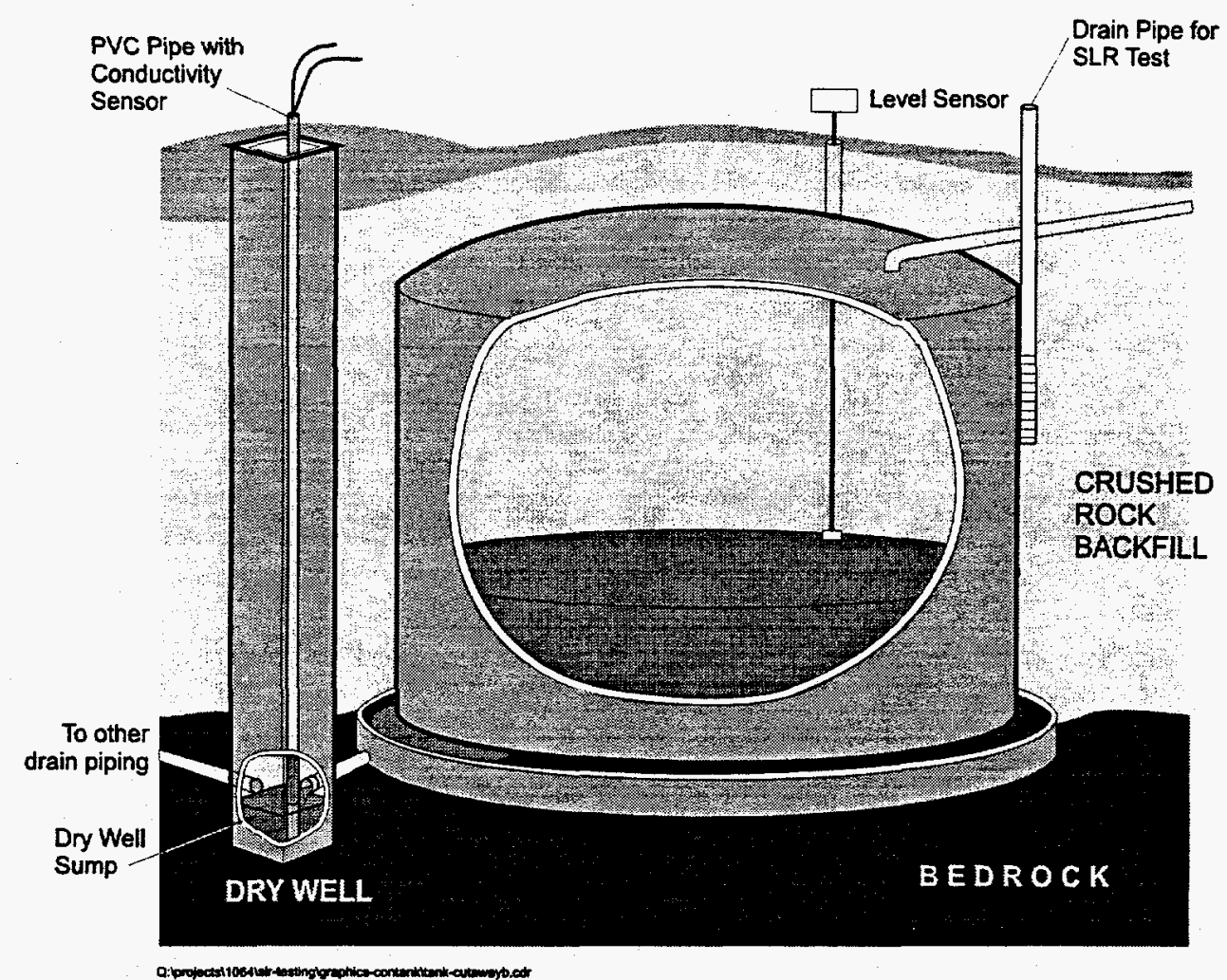

Fig. 2.2. Cut-away view of typical STF tank showing the tank, dry well, and drain pipe for the SLR test.

Proper installation and positioning of both the conductivity sensor within the dry well and the drain pipe adjacent to the tank are important to the success of the conductivity monitoring and SLR testing. The protective PVC well screen, in which the conductivity sensor is housed, must be as close as possible to the inlet pipe in the wall of the dry well. This maximizes the sensor's sensitivity to any liquids of different conductivity that might be flowing from the pad into the dry well. In both W-8 and W-9, the SLR drain pipe was installed as close to the outside wall of the tank as possible so that the liquid introduced into this pipe during the SLR test would simulate a release as realistically as possible by flowing down the side of the tank and onto the pad. The drain pipe installed at Tank W-9 worked correctly during the SLR test. The one installed at Tank W-8 did not, and a second drain pipe was therefore installed that subsequently did simulate the release successfully. Details of the baseline monitoring and SLR tests are discussed in Sects. 2.1 and 2.2. 


\subsection{BASELINE DRY WELL CONDUCTIVITY MONITORING}

The instrumentation and baseline dry well conductivity-monitoring data for DW-8 and DW-9 are presented in this section. The purpose of the baseline conductivity monitoring was to establish the normal range and statistics for conductivity measurements of the groundwater in the dry wells. This information was then compared with the changes in conductivity observed during the subsequent SLR tests.

The conductivity measurements were made using Great Lakes Instruments small-bore, electrodeless conductivity sensors (Model 3625E27). The sensors were calibrated before installation by the ORNL Instrumentation and Controls Division and set up with a range of 0 to $4000 \mu \mathrm{S} / \mathrm{cm}$. The sensors, submerged below the level of the groundwater at the bottom of the dry wells, are located inside a PVC well screen, which keeps them free of sediment and other material. Diagrams of the well screen and conductivity sensors in DW-8 and DW-9 are shown in Figs. 2.3 and 2.4, respectively. The sensors are controlled at the surface by a transmitter, allowing them to be powered by a $4-$ to $20-\mathrm{mA}$ instrument circuit. The surface transmitter also allows the sensors to be periodically field calibrated. For the baseline monitoring and SLR testing, measurements made by the sensors were sampled and recorded every $30 \mathrm{~min}$ with portable, battery-powered loggers.

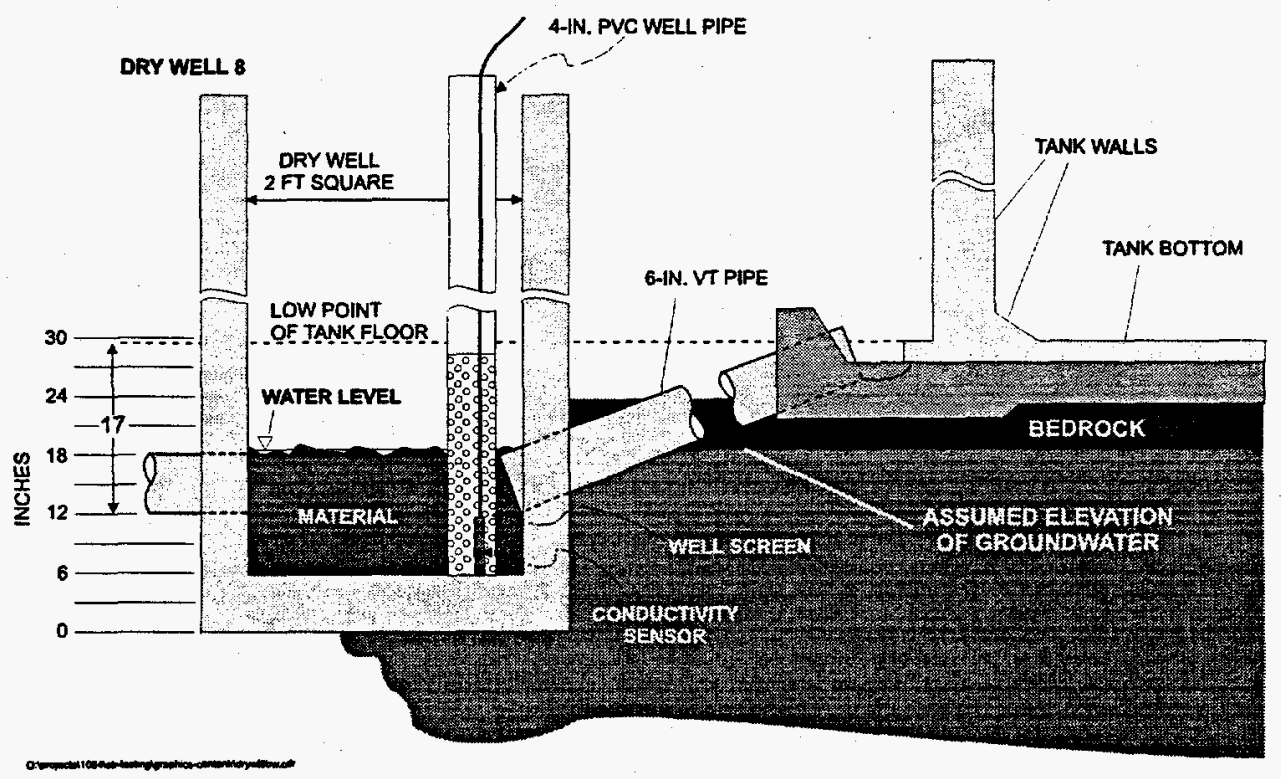

Fig. 2.3. Cross section of DW-8 showing the location of the PVC screen and riser, the conductivity sensor, and the level of water in the dry well.

As discussed in Chap. 1, a preliminary report on the results from Tank W-9 was issued at the end of July 1997 (Lockheed Martin Energy Systems, Inc. 1997b). These results are repeated here for the sake of completeness.

The baseline monitoring data for DW-9 were collected from 15 May through 16 June 1997. The data were downloaded from the logger weekly. The data files were processed and reviewed by Vista Research, Inc., and assembled into a single baseline data file. The baseline conductivity data for DW-9, plotted in $\mu \mathrm{S} / \mathrm{cm}$ versus time, are shown in Fig. 2.5. Cumulative rainfall data in inches for 


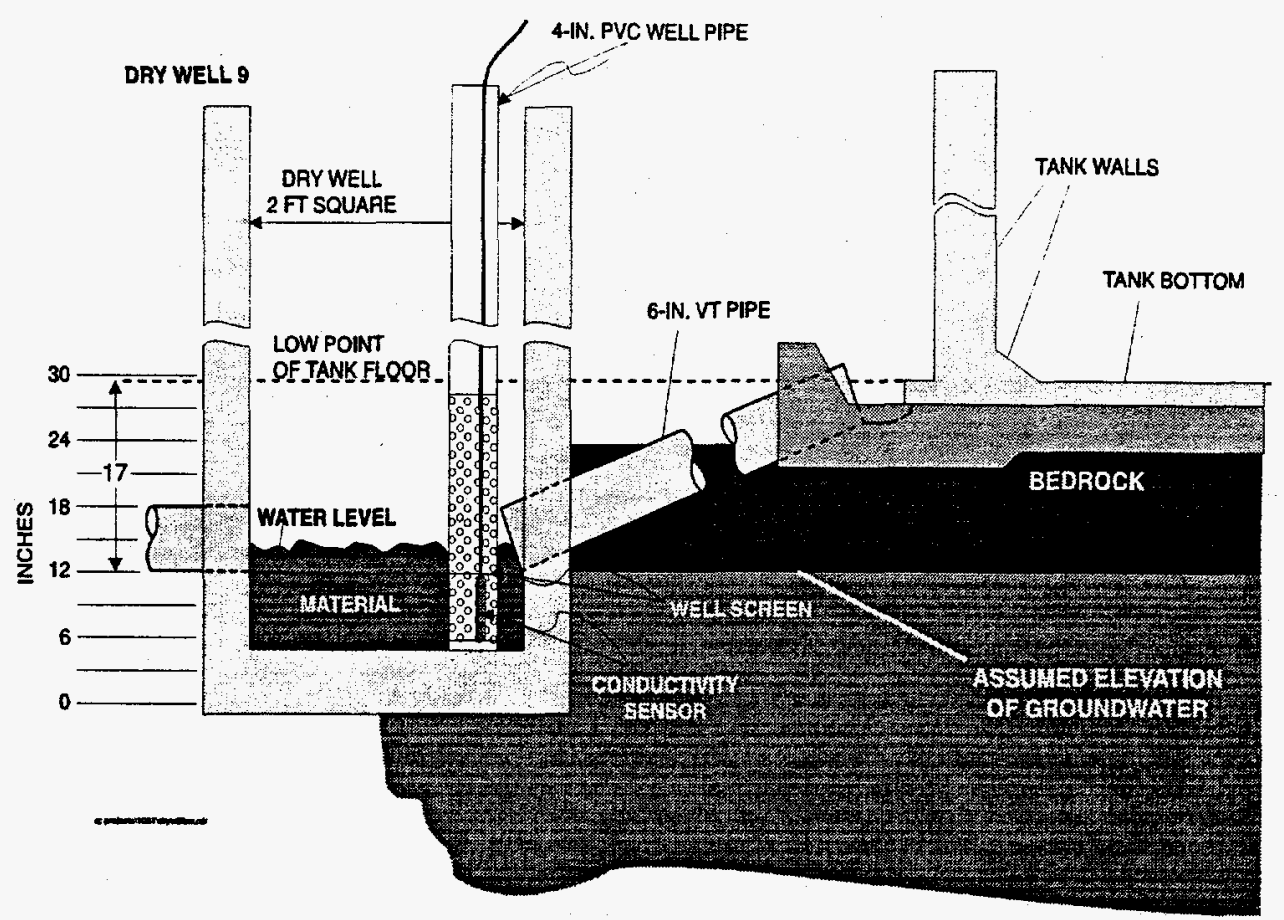

Fig. 2.4. Cross section of DW-9 showing the location of the PVC screen and riser, the conductivity sensor, and the level of water in the dry well.

the period indicated are also plotted. As can be seen in Fig. 2.5, the conductivity of the groundwater in DW-9 ranged from 210 to $370 \mu \mathrm{S} / \mathrm{cm}$, with a mean value of $310 \mu \mathrm{S} / \mathrm{cm}$ and a standard deviation of $30 \mu \mathrm{S} / \mathrm{cm}$. The typical range for groundwater in noncontaminated areas is from 200 to $500 \mu \mathrm{S} / \mathrm{cm}$. Small changes (decreases) in conductivity corresponding to rainfall events (seen as jumps or increases in cumulative rainfall) can be seen in the data. Overall, the measured conductivity levels remained fairly constant during the baseline monitoring. On the basis of these data and the

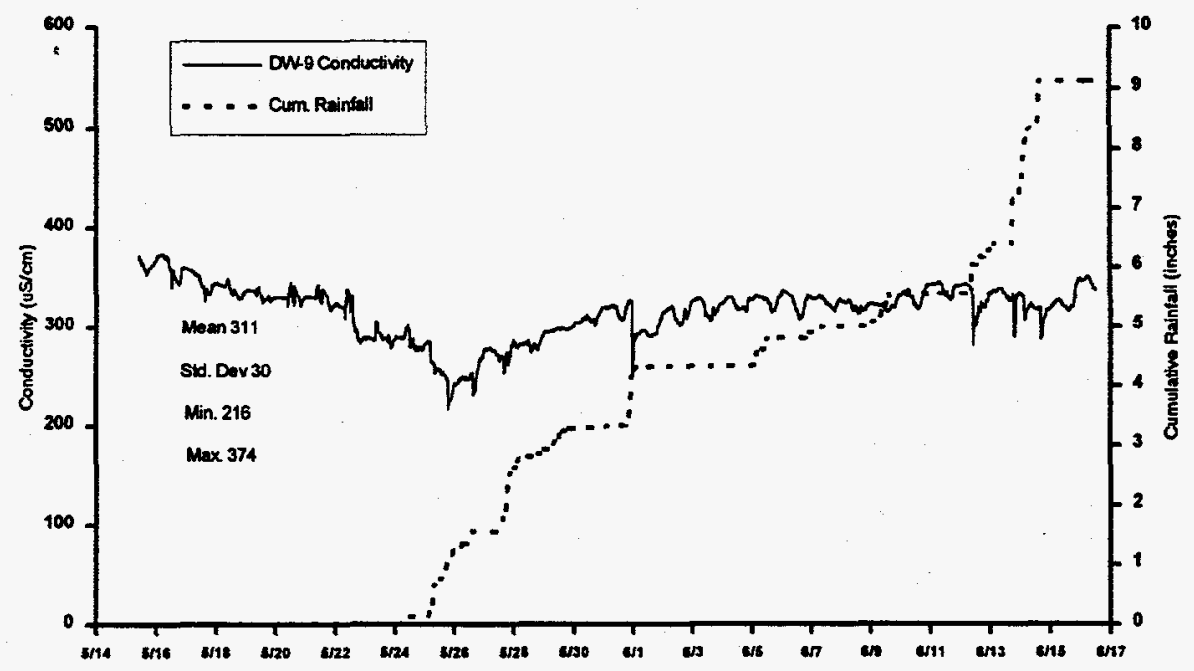

Fig. 2.5. Plot of DW-9 baseline conductivity and cumulative rainfall data. 
assumption that the conductivity method provides information regarding the liquid integrity of the tank (as will be shown later), the earlier findings that Tank W-9 is tight and leak free (Lockheed Martin Energy Systems, Inc. 1997) are confirmed.

On the basis of these data, a change in conductivity that was three standard deviations $(90+\mu \mathrm{S} / \mathrm{cm})$ above the maximum measured value of $370 \mu \mathrm{S} / \mathrm{cm}(\approx 460 \mu \mathrm{S} / \mathrm{cm})$ in DW-9 would be indicative of water with a higher conductivity getting into the dry well. If the conductivity were to increase significantly above the 460 value, a potential liquid release from Tank W-9 would be indicated. The results of the SLR test on DW-9, presented in the next section, show that even a very small simulated release causes the conductivity in DW-9 to increase significantly above the baseline measurements and the 460 value.

The baseline monitoring data for DW-8 were collected from 20 May through 27 July 1997 . The data were downloaded from the logger weekly. The data files were processed and reviewed by Vista Research, Inc., and assembled into a single baseline data file. The baseline conductivity data for DW-8, plotted in $\mu \mathrm{S} / \mathrm{cm}$ versus time, are shown in Fig. 2.6. Cumulative rainfall data in inches for the period indicated are also plotted. As can be seen in Fig. 2.6, the conductivity of the groundwater in DW-8 ranged from 200 to $520 \mu \mathrm{S} / \mathrm{cm}$, with a mean value of $350 \mu \mathrm{S} / \mathrm{cm}$ and a standard deviation of $80 \mu \mathrm{S} / \mathrm{cm}$. Small changes (decreases) in conductivity corresponding to rainfall events (seen as jumps or increases in cumulative rainfall) can be seen in the data.

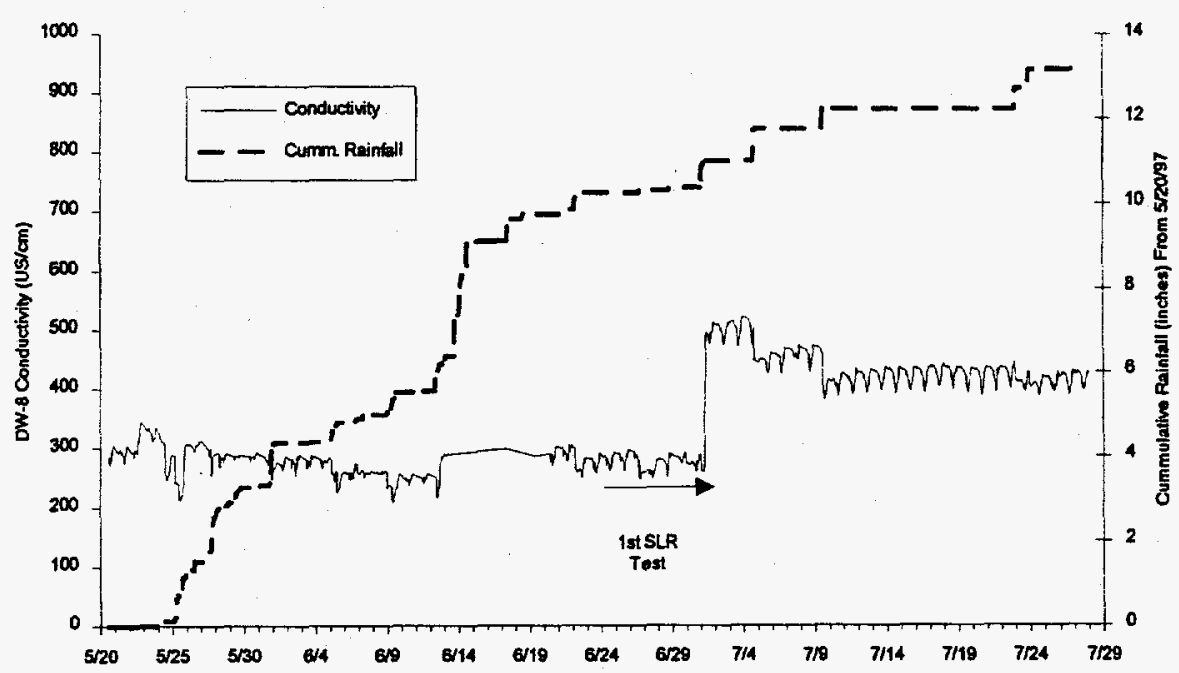

Fig. 2.6. Plot of DW-8 baseline conductivity, first SLR test and cumulative rainfall data.

On the basis of these data, a change in conductivity that was three standard deviations $(240+\mu \mathrm{S} / \mathrm{cm})$ above the maximum value of $520 \mu \mathrm{S} / \mathrm{cm}(\approx 760 \mu \mathrm{S} / \mathrm{cm})$ in DW-8 would be indicative of water with a higher conductivity getting into the dry well. If the conductivity were to increase significantly above the 760 value, a potential liquid release from Tank W-8 would be indicated.

An SLR test was attempted during this period (24 June to 1 July 1997). The arrow on the plot shows the time interval for the test. No response was observed in DW-8 during the testing until the rainfall event on $1 \mathrm{July}$. These results indicated that the drain pipe was too far from the edge of the 
tank and that the test solution had been draining into the backfill material rather than onto the pad at the base of Tank W-8. When it rained on 1 July, the infiltration of rainwater and the increased groundwater flow most likely flushed some of the test solution from the backfill into the dry well, causing the sudden jump in conductivity concentrations. Conductivity in DW-8 subsequently settled back down to a level slightly above the initial baseline value. It is likely that the presence of the SLR test solution in the backfill contributed to the increase in baseline readings. On 28 and $29 \mathrm{July}$, in preparation for a second SLR test on DW-8, a new drain pipe was installed closer to the edge of the tank, and the sensor in DW-8 was moved closer to the inlet drain leading from the tank pad. The results of the second test, presented in the next section, show that even a very small simulated release causes the conductivity in DW-8 to increase above the baseline measurements and the 760 value.

\subsection{SIMULATED LIQUID RELEASE TESTING ON TANKS W-8 AND W-9}

SLR testing was conducted first on Tank W-9, from 12:30 p.m. on 16 June 1997 through 8:30 a.m. on 20 June, a period of 92 hours. In this test, potassium chloride was mixed with water in a 55-gal drum in sufficient concentration to achieve a solution conductivity of about $15,000 \mu \mathrm{S} / \mathrm{cm}$. This value, which was selected because it is conservative, is at the low end of the range of conductivity of the liquids in the gunite tank; this range has been measured at $15,000 \mu \mathrm{S} / \mathrm{cm}$ to over $30,000 \mu \mathrm{S} / \mathrm{cm}$ (Lockheed Martin Energy Systems, Inc. 1997). A peristaltic pump was used to meter the flow of the SLR liquid from the drum into the drain pipe adjacent to Tank W-9. For the entire SLR test, the flow rate from the pump was calibrated and set to $0.5 \mathrm{gal} / \mathrm{h}$. This value was checked several times during the test by means of a graduated cylinder and a stop watch.

The conductivity measurements in DW-9 were recorded by the data logger every $30 \mathrm{~min}$. Manual readings were also taken from the data logger before the test and again a few hours after the test began. Within $3 \mathrm{~h}$ of the start of the SLR test (i.e., $3 \mathrm{~h}$ after the SLR liquid started draining down DP-9), the conductivity in DW-9 began to increase. Figure 2.7 is a plot of the DW-9 conductivity data, covering a period beginning about 3 days before the start of the SLR test and ending about 10 days after it. (Also shown is the cumulative rainfall data from the ORNL meteorological tower.) The increase in conductivity that resulted from the introduction of the SLR liquid into DP-9 can

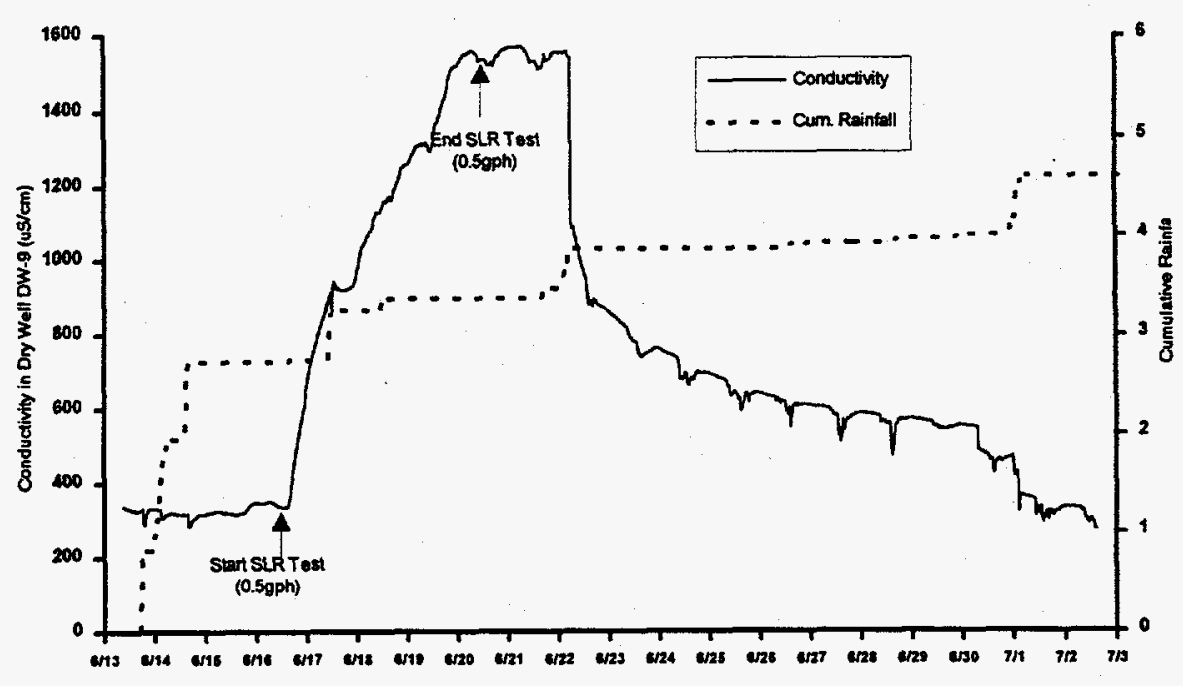

Fig. 2.7. Plot of SLR test on Tank W-9. 
easily be seen on the plot. Within a day, conductivity increased from approximately $370 \mu \mathrm{S} / \mathrm{cm}$ to more than $800 \mu \mathrm{S} / \mathrm{cm}$. During the $92-\mathrm{h}$ test, conductivity increased to more than $1500 \mu \mathrm{S} / \mathrm{cm}$.

The response in DW-9 to the $0.5-\mathrm{gal} / \mathrm{h}$ simulated release clearly demonstrates that monitoring the conductivity of the water in the dry well is an effective and sensitive method of release detection. Because the baseline conductivity of the groundwater has an average value that remains close to $311 \mu \mathrm{S} / \mathrm{cm}$, and because it increased to more than $1500 \mu \mathrm{S} / \mathrm{cm}$ with a simulated leak of just $0.5 \mathrm{gal} / \mathrm{h}$, these results also confirm the results of the prior analysis of the internal-level data-that Tank W-9 is not currently leaking. Because DP-9 was installed diametrically opposite DW-9 (see Fig. 2.1), these results also demonstrate that the concrete pad underlying W-9 is integral and free of cracks and fissures and that any liquid released from W-9 will drain into DW-9.

The cumulative rainfall data in Fig. 2.7 show some interesting effects. Before the SLR test, several inches of rain fell over the course of a couple of days. This caused a few blips in the baseline data but did not change these data significantly. This indicates that, when rainwater infiltrates a dry well containing groundwater, the resulting mix is slightly lower in conductivity. About $0.5 \mathrm{in}$. of rain fell on 17 June, during the SLR test. Although a slight blip can be seen in the conductivity data as a result of the infiltration of the rainwater, conductivity levels continued to increase after the rainfall event. Several days after the SLR test had ended, another $0.5 \mathrm{in}$. of rain was recorded (on 22 June). This event caused the concentration in DW-9 to decrease from $1500 \mu \mathrm{S} / \mathrm{cm}$ down to around $800 \mu \mathrm{S} / \mathrm{cm}$. The conductivity of the water in the dry well then decreased slowly over the next week. Another rainfall event on 30 June reduced the concentration further, to within the normal baseline range. These data indicate that groundwater and infiltrating rainwater slowly flow through the dry well and that the baseline measurements made in DW-9 are representative of the normal concentrations of groundwater and infiltrating rainwater. They also show that even very small simulated leaks can be easily detected above the normal flushing action of the groundwater and the infiltration of rainwater.

The baseline conductivity-monitoring effort and the results of the SLR test provide sufficient data to establish a preliminary release detection threshold for Tank W-9. As noted in Sect. 2.1, a conductivity value of about $460 \mu \mathrm{S} / \mathrm{cm}$ is approximately three standard deviations above the maximum value recorded in DW-9 during the baseline study there. If the conductivity in DW-9 exceeds this value, then there is at least a $99 \%$ chance that the change is more than just random error. That is, should such a change occur, the tank may be leaking. Although a value of about 460 to $500 \mu \mathrm{S} / \mathrm{cm}$ might be used as a release detection threshold, it might also be too low and thus lead to a high incidence of false alarms. This is because the conductivity of the groundwater in DW-9 has not been studied year-round, and this dry well might experience larger fluctuations during other parts of the year. To prevent false alarms from interfering needlessly with the treatability study and waste removal program and yet retain the sensitivity to detect small leaks, a preliminary threshold of $900 \mu \mathrm{S} / \mathrm{cm}$ has been selected. Until further baseline data are collected and analyzed, this value represents a reasonable compromise between achieving a high probability of detecting a small release (a few tenths of a gallon per hour) and maintaining a low probability of false alarm. As more data are collected and a more confident estimate of the statistics of the DW-9 conductivity values is developed, the threshold value can be changed, if that is indicated.

Two SLR tests were conducted on Tank W-8. The first was unsuccessful because the drain pipe was not located close enough to the edge of the tank to effectively simulate a liquid release (as discussed in Sect. 2.1). For the second test, a new drain pipe was installed closer to the edge of the tank, and the sensor in the dry well was repositioned closer to the inlet pipe leading from the tank pad. These activities were conducted on 27 and 28 July 1997. The second test was started at 
9:30 a.m. on 1 August 1997 and ended 7:50 a.m. on 11 August. The test was conducted according to the same procedures used for the SLR test on Tank W-9. A $15,000-\mu \mathrm{S} / \mathrm{cm}$ test solution was metered into the drain pipe at $0.5 \mathrm{gal} / \mathrm{h}$ using a peristaltic pump.

The conductivity measurements in DW-8 were recorded by the data logger every $30 \mathrm{~min}$. Manual readings were also taken from the data logger before the test and again a few hours after the test began. Fig. 2.8 is a plot of the DW- 8 conductivity data and the cumulative rainfall data from the ORNL meteorological tower. The increase in conductivity that resulted from the introduction of the SLR liquid into DP-8 can easily be seen. During the test, conductivity increased from a baseline of $370 \mu \mathrm{S} / \mathrm{cm}$ to approximately $1000 \mu \mathrm{S} / \mathrm{cm}$. This is a significant increase above the three standard deviations over the baseline maximum value $(760 \mu \mathrm{S} / \mathrm{cm})$ discussed in Sect. 2.1.

The response in DW-8 to the $0.5-\mathrm{gal} / \mathrm{h}$ simulated release clearly demonstrates that monitoring the conductivity of the water in the dry well is an effective and sensitive method of release detection. Because the baseline conductivity of the groundwater had an average value of approximately $370 \mu \mathrm{S} / \mathrm{cm}$, and because it increased to approximately $1000 \mu \mathrm{S} / \mathrm{cm}$ with a simulated leak of just $0.5 \mathrm{gal} / \mathrm{h}$, these results also confirm the results of the prior analysis of the internal-level data-that Tank W-8 is not currently leaking. Because DP-8 was installed diametrically opposite DW-8 (see Fig. 2.1), these results also demonstrate that the concrete pad underlying W-8 is integral and free of cracks and fissures and that any liquid released from W-8 will drain into DW-8.

In comparing the results of the SLR tests on W-9 and W-8, one sees that the conductivity values in DW-9 increased faster than in DW-8. There are a number of factors that could account for the difference in the two tests, including backfill compaction and the distance between the drain pipe and the edge of the tank. It is believed, however, that the main factor is the difference in elevation between the two tank and dry well systems. In the STF (Fig. 2.1), the northern row of tanks (W-5, $W-7$, and W-9) is a foot or more higher in elevation than the southern row (W-6, W-8, and W-10). As a result, the groundwater level is at least a foot deeper in DW-6, DW-8, and DW-10. This is

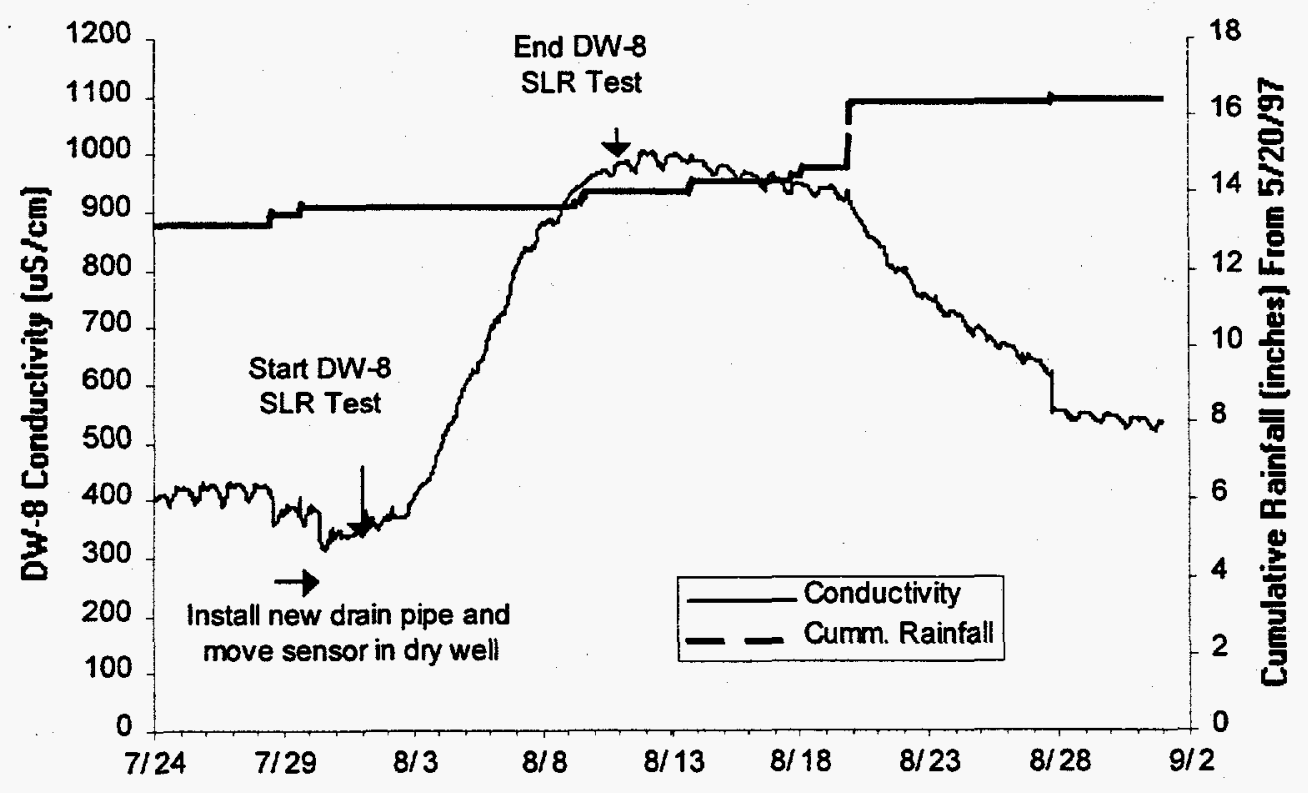

Fig. 2.8. Plot of SLR test on Tank W-8. 
confirmed by field measurements that show the water level in the bottom of DW-8 to be higher than in DW-9, as illustrated in Figs. 2.3 and 2.4. In DW-9 the water level is below the inlet drain, allowing fluids from the tank pad to drain efficiently into the dry well. In DW-8 the water level is above the top of the inlet pipe, a condition that most likely impedes to some extent the movement of fluids from the tank pad into the dry well. The reduced flow efficiency into DW-8 most likely accounts for the slower response to the SLR test. The cumulative rainfall plot on Fig. 2.8 shows a significant rainfall event on 20 August 1997. This rainfall event appears to have helped increase the rate of decrease in the conductivity concentrations in DW-8 following the SLR test.

In the SLR test for DW-9, approximately $25 \mathrm{gal}$ of liquid (at $0.5 \mathrm{gal} / \mathrm{h}$ ) was released before the concentration in that dry well increased above $900 \mu \mathrm{S} / \mathrm{cm}$; for DW-8, approximately 150 gal was released before the concentration increased above $900 \mu \mathrm{S} / \mathrm{cm}$. In both cases, a relatively small quantity of liquid was released before the proposed alarm level was reached. Thus, the SLR test results from Tank W-8 are not significantly different from the results for Tank W-9, showing that the CMM is an effective external release detection method and that the same monitoring procedures and alarm thresholds discussed above for DW-9 can be used for DW-8.

\section{DRY WELL CONDUCTIVITY-MONITORING RESULTS FOR TANK W-10}

Dry well conductivity monitoring and SLR testing were also conducted on Tank W-10 in preparation for the eventual waste removal operations at this tank. DW-10 was instrumented at the same time as DW-8 and DW-9, and a drain pipe was installed adjacent to Tank W-10 for SLR testing. A cross section of DW-10 showing the conductivity sensor installation and the groundwater level is provided in Fig. 3.1. As shown, the water level in DW-10 is above the top of the inlet pipe, just as it is in DW-8 (as discussed in Chap. 2).

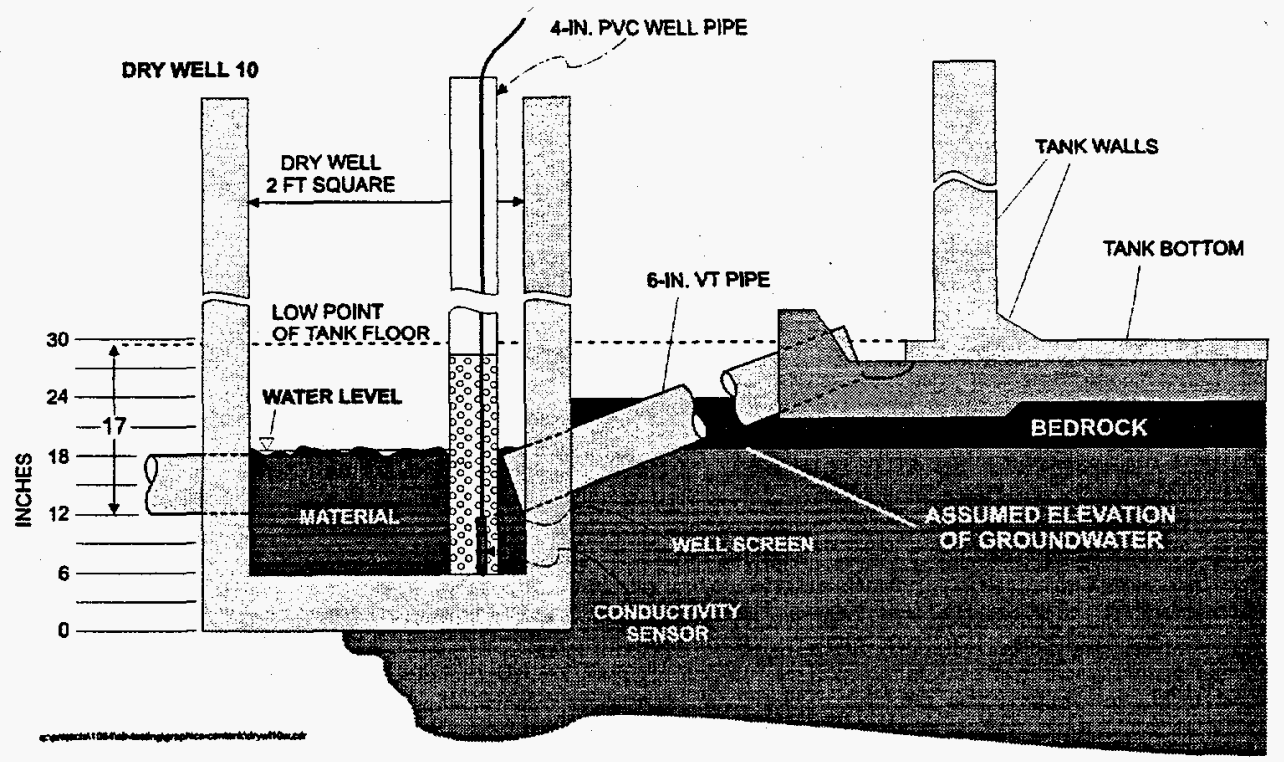

Fig. 3.1. Cross section of DW-10. 
The baseline data collection and SLR testing for Tank W-10 followed the same procedures used for W-8 and W-9. Conductivity monitoring in DW-10 began on 10 May 1997; SLR testing was started on 20 May 1997 and ended on 23 June. A plot showing the baseline monitoring and SLR test data for DW-10 is provided in Fig. 3.2. The baseline conductivity between 20 May and 23 June had a mean value of $300 \mu \mathrm{S} / \mathrm{cm}$, a standard deviation of $10 \mu \mathrm{S} / \mathrm{cm}$, and ranged from 270 to $320 \mu \mathrm{S} / \mathrm{cm}$. These values are consistent with DW-8 conductivity values for the same period ( 280 mean $\mu \mathrm{S} / \mathrm{cm}$, $20 \mu \mathrm{S} / \mathrm{cm}$ standard deviation). During the SLR test, the conductivity in DW-10 increased from approximately $300 \mu \mathrm{S} / \mathrm{cm}$ to $410 \mu \mathrm{S} / \mathrm{cm}$. The increase is clearly the result of the SLR test and was not affected by rainfall, as shown on Fig. 3.2. The test was terminated after 3 days because it had successfully demonstrated that a response could be seen in DW-10. Even though this response was less pronounced than that seen in DW-9 (indicating that a significant portion of the test liquid was

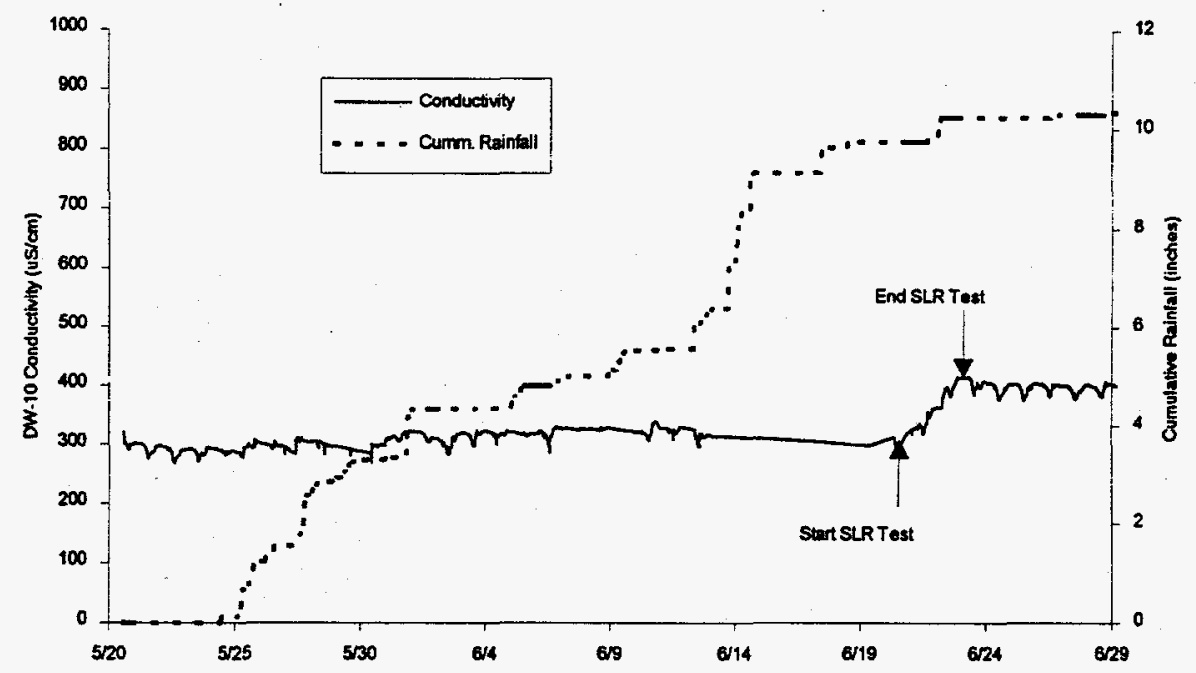

Fig. 3.2. Plot of DW-10 baseline conductivity, SLR test and cumulative rainfall data.

draining into the backfill and not onto the pad), the results nevertheless showed the continuity of the W-10 tank pad and dry well system and demonstrated that if a release from W-10 were to occur, it would be detected by the CMM. This is similar to what happened during the first SLR test at DW-8. The SLR tests on tanks W-8 and W-10 also showed that the enough residual test solution was getting into the backfill material to increase the baseline conductivity concentrations measured in the dry wells. As a result, additional testing for tank pad and dry well connectivity in the STF will employ deionized water as a test solution; the high-conductivity solution will be used only where deemed necessary to confirm that potential releases can be detected.

\section{MONITORING PLAN}

Groundwater conductivity measurements in DW-8, DW-9, and the other gunite tanks in the STF will be the primary means for release detection and for monitoring tank integrity. Accordingly, the conductivity sensors in DW-9 and DW-8 will continue to be used to collect baseline conductivity data and conduct the monitoring operations for Tanks W-9 (the primary consolidation tank) and W-8 (the backup tank), respectively. The monitoring sensors will be connected to the Waste Operations Control Center or to the waste removal equipment control center. The system will be set up to 
provide the operators with real-time data and conductivity threshold alarms. The preliminary alarm threshold for the tanks will be a conductivity level of $900 \mu \mathrm{S} / \mathrm{cm}$. Procedures will be prepared for the operators who will monitor W-9, W-8, and the other STF tanks during waste removal operations.

In addition to the continuous monitoring of DW-8 and DW-9, dry well conductivity data will be collected from each of the other four tanks in the STF in preparation for and during waste removal operations. To ensure that the CMM is viable for each tank, an SLR test will be conducted and baseline data will be collected before sluicing (waste removal) operations begin. The CMM data will continue to be logged to document operating conditions and provide additional supporting data for baseline conditions and alarms. The data will be compiled and quarterly reports will be prepared to document the monitoring results. The first quarterly data report will be completed in November 1997 and will include the monitoring data for dry wells DW-8, DW-9, and DW-10 through the end of October 1997. Additional dry wells will be added as the work in the STF progresses.

The conductivity sensors in the dry wells were calibrated by the ORNL Instrumentation and Controls Division before installation. The sensors will be field-calibrated approximately every 3 months. The transmitters that control the sensors have shown some sensitivity to moisture and heat. Routine maintenance checks will be performed on the equipment to make sure the sensors are operating correctly.

\section{CONCLUSIONS AND RECOMMENDATIONS}

The work reported here makes several important points regarding the conductivity method, the integrity of the W-8 and W-9 tank systems, and the utility of the CMM as it is applied to the GAAT treatability study and waste removal program. First, the body of the work shows that the method is a viable tool for monitoring the integrity of the GAAT during waste removal operations. Further, unlike internal monitoring schemes, the conductivity method works well even while in-tank operations are ongoing. Second, the monitoring program is economical and requires no new instrumentation to be added to the tanks that could interfere with the remediation of those tanks. The probes that are installed are external to the tank, easy to service, and relatively inexpensive. Third, a preliminary release-detection threshold has been established for the tanks that will allow reliable detection of small leaks with a low probability of false alarm. And lastly, the monitoring program that has been implemented around the conductivity method is a $24-\mathrm{h} /$ day program that is simple and intuitive and requires little operator training.

Regarding the W-8, W-9, and W-10 tank systems, the results of the work reported here validate and underscore the liquid integrity assessment made earlier, which used the changes in level over time as the sensed quantity. Simply put, W-8, W-9, and W-10 are not leaking. The baseline and SLR data quite conclusively show this. Further, because the drain pipes are located diametrically opposite the dry wells, the SLR test results show that the concrete pads beneath the tanks are not cracked or fissured in any way that would prevent a release from being detected. In addition, the data indicate that the STF drain system is working properly. That is, it appears from the SLR data that any releases from W-8, W-9, or W-10 will be captured by the drain system and carried to Pump Station 1 . The SLR testing for DW-8, DW-9, and DW-10 show that the dry well conductivity monitoring will be effective in detecting potential releases from the tanks during waste removal operations. Additional SLR testing, through the use of deionized water and possibly the high-conductivity solution, will be conducted on the other three tanks in the STF (W-5, W-6, and W-7) to verify that the CMM will work on these tanks as well. A test will also be conducted to verify the continuity of the drain system 
between the STF and Pump Station 1. Results of these tests will be documented in the quarterly reports.

\section{REFERENCES}

Lockheed Martin Energy Systems, Inc., 1996. Preliminary Evaluation of Liquid Integrity Monitoring Methods for Gunite and Associated Tanks at the Oak Ridge National Laboratory, ORNL/ER-349, Lockheed Martin Energy Systems, Inc., Oak Ridge, Tenn.

Lockheed Martin Energy Systems, Inc., 1997a. Evaluation and Monitoring Plan for Consolidation Tanks: Gunite and Associated Tanks Operable Unit, Waste Area Grouping 1, Oak Ridge National Laboratory, Oak Ridge, Tennessee, ORNL/ER-396, Lockheed Martin Energy Systems, Inc., Oak Ridge, Tenn.

Lockheed Martin Energy Systems, Inc., 1997b. Baseline Monitoring and Simulated Liquid Release Test Report for Tank W-9, Oak Ridge National Laboratory, Oak Ridge, Tennessee, ORNL/ER-410, Lockheed Martin Energy Systems, Inc., Oak Ridge, Tenn.

Vista Research, Inc., 1996. Simulated Liquid Release Demonstrations on Gunite Tanks $W-3$ and W-4 in the North Tank Farm, Vista Research Report 1060-TR-96-001, Vista Research, Inc., Oak Ridge, Tenn. 


\section{DISTRIBUTION}

1. L. V. Asplund

2. O. W. Hale

3. L. Holder, Jr.

4. M. A. Johnson

5. T. M. Koepp

6. P. T. Owen

7. L. B. Raulston

8. A. D. Reynolds

9. . S. D. Van Hoesen

10. Central Research Library

11. File-EMEF DMC-RC

12-21. J. G. Morse, Vista Research, Inc., 101 N. Rutgers Ave., Oak Ridge, TN 37830 